\title{
SC|AZ
}

\section{A expansão das tecnologias de informação e comunicação em escolas brasileiras: Limites e possibilidades das políticas públicas}

\author{
Daniel Santos Braga ${ }^{1}$ \\ Dina Mara Pinheiro Dantas²
}

\section{Resumo}

Este artigo tem como objetivo discutir a utilização das tecnologias digitais de informação e comunicação em escolas brasileiras e a repercussão das políticas públicas para sua expansão. Inicialmente foram apresentados os principais programas desenvolvidos no Brasil nas últimas décadas e em seguida, foram analisados dados educacionais extraídos do Censo Escolar e dos questionários contextuais do SAEB. A pesquisa tem como achados que as políticas públicas efetivadas a partir dos anos 2000 ampliaram significativamente a infraestrutura das escolas para o uso de tecnologias digitais como recursos pedagógicos. No entanto, com o tempo, os equipamentos escolares foram sendo subutilizados ou se tornaram obsoletos, apresentando piora em todos os itens analisados. Nesse sentido, foi possível destacar as possiblidades e os limites das políticas públicas de expansão da utilização das tecnologias digitais como instrumentos pedagógicos na educação básica brasileira.

\section{Palavras-chave}

Tecnologias digitais. Políticas Educacionais. Censo Escolar. SAEB.

Recebido em: 06/05/2019

Aprovado em: 11/09/2019

\footnotetext{
${ }^{1}$ Professor de cursos de formação de professores (Pedagogia e Letras) do Centro Universitário Newton Paiva e Professor Substituto do Departamento de Ciências aplicadas à Educação da Faculdade de Educação da Universidade Federal de Minas Gerais (UFMG). Doutorando em educação pela UFMG, Belo Horizonte, Minas Gerais, Brasil.

E-mail: danielsantosbraga@gmail.com

${ }_{2}^{2}$ Possui graduação em Pedagogia pela Universidade Federal do Ceará (2006) e mestrado em Educação pela Universidade Federal do Ceará (2010). Coordenadora e Professora do curso de Pedagogia da Universidade do Estado de Minas Gerais unidade Divinópolis (UEMG), Minas Gerais, Brasil.

E-mail: dinamara@gmail.com
} 


\title{
The expansion of information and communication technologies in Brazilian schools: limits and possibilities of public policies
}

\begin{abstract}
The article objective is discuss the use of digital information and communication technologies in Brazilian schools and the repercussion of public policies for its expansion. Initially, we presents the main programs developed in Brazil in the last decadesand then, the educational data extracted from the School Censusand the contextual questionnaires of the SAEB we reanalyzed. The research finds that the public policies implemented since the 2000 s significantly expanded the infrastructure of schools for the use of digital technologies as pedagogical resources. However, over time, school equipment has been underusedor be come obsolete, presenting worsening in all item sanalyzed. In thissense, it was possibleto high light the possibilities and limits of public policies to expand the use of digital technologies as pedagogical instruments in Brazilian basic education.
\end{abstract}

\section{Keywords}

Digital Technologies. Educational Policies. School Census. SAEB. 


\section{Introdução}

A utilização das Tecnologias Digitais da Informação e Comunicação (TDIC) na área educacional avançou consideravelmente nos últimos anos, sendo objeto de estudos e pesquisas que apontavam que o uso do computador pode melhorar o desenvolvimento cognitivo e o desempenho escolar dos estudantes. Segundo Valente (1995), a difusão dessas teorias logo se tornou popular nos meios acadêmicos e escolares, criando a necessidade de inseri-las na escola a partir de uma perspectiva pedagógica. Esse movimento pressionou os governos para a adoção de uma série de políticas públicas que objetivavam dar corpo a essas novas necessidades, adequando as escolas no tocante a sua infraestrutura, seus equipamentos e recursos humanos.

No entanto, apesar das grandes possibilidades que os recursos tecnológicos representam para as práticas educativas, a implementação das políticas públicas de expansão da utilização da TDIC no Brasil se deu em um contexto de grande complexidade, que, em grande medida, se apresentaram como limites para a sua expansão. As dimensões continentais do país e sua desigualdade estrutural, evidenciada pela assimetria fiscal de seus entes federados, e a coexistência de sistemas educacionais estaduais e municipais autônomos, fez com que os recursos tecnológicos de informática nas escolas não fossem distribuídos de forma igualitária. Mesmo com grande desafio, essas políticas têm alcançado algum êxito na disseminação de recursos destinados ao uso das TDIC por estudantes da educação básica em todo o país.

O objetivo deste artigo é discutir esses limites e as possibilidades das políticas de expansão das TDIC em escolas públicas brasileiras da educação básica. Para isso, inicialmente foi realizado um levantamento do quadro normativo nacional acerca da política de expansão das TDIC. Em seguida, a partir da análise de conteúdo, se discutiu os aspectos dessa legislação, sua pertinência e adequabilidade às discussões teóricas do campo da Educação e Tecnologia. Foram analisados também dados secundários de órgãos governamentais, especialmente os do Censo Escolar e do Sistema Nacional de Avaliação da Educação Básica (SAEB), produzidos pelo Instituto Nacional de Estudos e 
Pesquisas Educacionais Anísio Teixeira (INEP). Para fins deste trabalho iremos abordar como TDIC os aspectos relativos ao uso de recursos computacionais, de informática e de internet para fins didáticos.

O texto está organizado em três partes. Na primeira seção foram discutidos aspectos da política tecnológica desenvolvida nas últimas décadas no Brasil. $\mathrm{Na}$ segunda seção foram abordadas as repercussões dessa política no campo da educação e como tem se dado a inserção e a utilização de computadores nas escolas. A terceira e última parte do texto apresenta análise quantitativa da presença de itens destinados a utilização das TDIC nas escolas, suas condições uso e seu estado de conservação.

\section{Políticas de Informática Educativa}

O Brasil iniciou seu programa de desenvolvimento tecnológico com relativo atraso em relação a outros países do mundo, tendo como marco nos anos de 1970 a criação e institucionalização da Comissão Coordenadora das Atividades de Processamento Eletrônico, a Empresa Digital Brasileira e a Secretaria Especial de Informática. Esta última era ligada a presidência e tinha como objetivo controlar o desenvolvimento tecnológico no país. Esses órgãos buscaram fomentar e estimular a informatização da sociedade brasileira, voltada para a capacitação científica e tecnológica capaz de promover a autonomia nacional, baseada em princípios e diretrizes fundamentados na realidade do Brasil e decorrente das atividades de pesquisas e da consolidação da indústria nacional. Para o alcance de seus objetivos seria preciso estender as aplicações da informática aos diversos setores e atividades da sociedade, no sentido de examinar as diversas possibilidades de parceria e solução aos problemas nas diversas áreas intersetoriais, como a energia, saúde, agricultura, cultura e defesa nacional (MORAES, 1997).

Dentre os setores que receberam investimentos para o desenvolvimento, a educação foi priorizada pela sua presença e importância social. Dessa forma, passou a ser o setor de maior importância para disseminação e aceitação da modernidade tecnológica. O Ministério da Educação (MEC), no início da década 
de oitenta, ficou responsável pela elaboração de projetos que viabilizavam a disseminação e a formação da informática na sociedade. Os primeiros estudos com o objetivo de enraizar a informática, contou com criação e desenvolvimento com as instituições: Conselho Nacional de Pesquisas, Financiadora de Estudos e Projetos e Secretaria Especial de Informática da Presidência da República (SEI/PR), voltada para a criação de núcleos interdisciplinares de pesquisa e formação de recursos humanos em universidades públicas.

Com os resultados preliminares desses estudos, observou-se a necessidade de elaborar outro projeto que complementasse e lhe desse maior suporte. Um dos dados observados e avaliados foi o da formação do professor para trabalhar com a tecnologia na educação. Essa avaliação mostrou a necessidade de rever a postura do professor na utilização dos computadores. Para essa demanda o MEC criou o Programa de Ação Imediata em Informática na Educação da Educação Básica. Esse programa tinha como objetivo capacitar professores (FORMAR) e implantar a infra-estrutura dos ambientes, que foram chamadas de Centros de Informática Aplicada à Educação de 10 e 20 grau (CIEd), Centros de Informática na Educação Tecnológica - CIET e Centro de Informática na Educação Superior (CIES). A cada centro competia a criação da sua proposta pedagógica e uso dos laboratórios, contribuindo para autonomia dos centros de informática.

O Brasil, contando com uma base teórica consistente e com experiências positivas dos projetos-pilotos, fez com que o MEC ampliasse sua política de implantação. O resultado desse evento foi o Programa Nacional de Informática na Educação (PRONINFE), que visava desenvolver a informática educativa no Brasil. O objetivo do PRONINFE era utilizar atividades e projetos articulados e convergentes, possuindo fundamentação pedagógica, sólida e atualizada, de modo a garantir a unidade política, técnica e científica imprescindível ao êxito dos esforços e investimentos envolvidos.

Essas políticas públicas desencadeadas durante a década de oitenta foram essenciais para a ampliação da informática educativa na década seguinte, criando as bases da política nacional de informática na educação. Em um 
contexto da intensificação da globalização e a ampliação das tecnologias de informação e comunicação na sociedade nos anos de 1990, foi demandado ao país uma preocupação ainda maior com a universalização e a democratização do ensino e dos usos das TDIC. Um exemplo desse esforço foi a aprovação da Lei ${ }^{\circ}$ 10.172, de 09 de janeiro de 2001, que instaurou o Plano Nacional de Educação (PNE). Dentre outras medidas, o plano em sua meta 6 -'Educação a Distância e Tecnologias Educacionais', apresentava um diagnóstico que compreendia a Educação a Distância como um importante instrumento para a superação das graves distorções e desigualdades da educação do país.

Além disso, o plano estabelecia também que as TDIC poderiam contribuir na elaboração do currículo e na melhoria da qualidade do ensino presencial. Conforme o texto do próprio PNE (2001) "é fundamental equipar as escolas com multimeios, capacitar os professores para utilizá-los, especialmente na Escola Normal, nos cursos de Pedagogia a nas Licenciaturas, e integrar a informática na formação regular dos alunos.” Para a efetivação dos objetivos e metas previstas no plano fez-se necessário a iniciativa e a colaboração da União no cumprimento. Dentre as principais metas relativas às tecnologias como recurso didático ao professor no ensino presencial destacava-se no PNE de 2001 a instalação de computadores em escolas públicas de ensino fundamental e médio, promovendo condições de acesso à internet; a capacitação de professores multiplicadores em informática da educação; a capacitação de professores e técnicos em informática educativa e ampliar em $20 \%$ ao ano a oferta dessa capacitação; e equipar, em dez anos, todas as escolas de nível médio e todas as escolas de ensino fundamental com mais de 100 alunos, com computadores e conexões internet que possibilitassem a instalação de uma Rede Nacional de Informática na Educação e desenvolver programas educativos apropriados, especialmente a produção de softwares educativos de qualidade.

Ainda que muitas de suas metas não tenham sido alcançadas, o PNE de 2001 teve como efeito a consolidação da percepção das necessidades das tecnologias digitais e a demanda da inclusão digital nas escolas. O segundo PNE, compreendendo o decênio 2014-2024, instituído pela Lei 13.005, de 25 de junho de 2014, estabeleceu novas metas e objetivos para a melhoria da oferta da 
educação escolar no país além de repetir àquelas que não haviam sido cumpridas do plano anterior.

No tocante às tecnologias, a estratégia 12 da meta 7 almeja incentivar 0 desenvolvimento, selecionar, certificar e divulgar tecnologias educacionais para a educação básica e incentivar práticas pedagógicas inovadoras que assegurem a melhoria do fluxo escolar e a aprendizagem, assegurada a diversidade de métodos e propostas pedagógicas, com preferência para softwares livres e recursos educacionais abertos, bem como o acompanhamento dos resultados nos sistemas de ensino em que forem aplicadas. Já em sua estratégia 15 da mesma meta, o plano prevê a universalização, até o quinto ano de sua vigência, $\mathrm{o}$ acesso à rede mundial de computadores em banda larga de alta velocidade $\mathrm{e}$ triplicar, até o final da década, a relação computador/aluno nas escolas da rede pública de educação básica, promovendo a utilização pedagógica das tecnologias da informação e da comunicação. Ainda para a meta 7, a estratégia 20 planeja prover equipamentos e recursos tecnológicos digitais para a utilização pedagógica no ambiente escolar a todas as escolas públicas da educação básica, criando, inclusive, mecanismos para implementação das condições necessárias para a universalização das bibliotecas nas instituições educacionais, com acesso a redes digitais de computadores, inclusive a internet.

A meta 9 na estratégia 11 também aponta caminhos para as TDIC ao estabelecer a implementação de programas de capacitação tecnológica da população jovem e adulta, direcionados para os segmentos com baixos níveis de escolarização formal e para os alunos com deficiência, articulando os sistemas de ensino, a Rede Federal de Educação Profissional, Científica e Tecnológica, as universidades, as cooperativas e as associações, por meio de ações de extensão desenvolvidas em centros vocacionais tecnológicos, com tecnologias assistivas que favoreçam a efetiva inclusão social e produtiva dessa população.A meta 15 também aborda o assunto ao tratar da formação de professores. A estratégia 6 aponta uma reforma curricular dos cursos de licenciatura de forma a estimular uma renovação pedagógica, de forma a incorporação das TDIC, em articulação com a base nacional comum dos currículos da educação básica. 


\section{A informática na escola atualmente}

A presença do computador na educação continua a evoluir consideravelmente, graças à divulgação de estudos e pesquisas que afirmam e apontam que o uso de tecnologias digitais, como o computador pode melhorar o desenvolvimento cognitivo e o desempenho escolar dos estudantes (PAPERT, 1994; VALENTE, 1999; FREIRE, 2002; FREIRE; GUIMARÃES, 2011 ; BELLONI, 2006; BELLONI; GOMES, 2008; ALMEIDA, M. E. B.; VALENTE, J. A., 2011). Com isso, a discussão sobre o uso do computador no meio acadêmico e educacional popularizou-se, não somente por inserir tecnologias digitais no espaço escolar, bem como discutir seu sentido pedagógico.

Desse modo, para cumprir os compromissos assumidos, o governo reestruturou a Política Nacional de Informatização Educacional, através do Programa Nacional de Tecnologia Educacional (ProInfo), envolvendo parceria dos ministérios de Planejamento, Educação, Comunicação, Ciências e Tecnologia, objetivando: disponibilizar recursos considerados educativos auxiliando o professor em sua prática de sala ou no laboratório de informática, implantar laboratórios de informática em escolas e prever também acesso a internet (BRASIL, 2009).

A preocupação do governo com relação a formação do professor para trabalhar nesses novos ambientes, os Laboratórios de Informática Educativa (LIE), refere-se ao fato de que os laboratórios são de fato um recurso a mais para o professor. A partir de então, o governo criou o "ProInfo Integrado", visando além da instalação dos computadores, a oferta de conteúdos e recursos multimídias e digitais pelo Portal do Professor, pela TV Escola e DVD Escola, pelo Domínio Público e pelo Banco Internacional de Objetos Educacionais. Atualmente, o "Proinfo Integrado", oferece dois cursos aos professores da rede pública: mídias na educação e tecnologias na educação. Ambos visam dar formação ao professor para conhecer os recursos e como agregá-los, complementando sua aula com esses materiais, uma vez que tais recursos podem auxiliar os conteúdos trabalhados nos livros didáticos. 
A Secretaria de Educação a Distância (SEED) foi a responsável por desenvolver programas e ações para o cumprimento previsto como meta 6 do PNE de 2001 a 2010. São eles: Domínio Público - biblioteca virtual; DVD Escola; E-ProInfo; ETec Brasil; Programa Banda Larga nas Escolas; Proinfantil; ProInfo Integrado; TV Escola; Sistema Universidade Aberta do Brasil (UAB); Banco Internacional de Objetos Educacionais; Portal do Professor; Programa Um Computador por Aluno - Prouca; Projeto Proinfo. Algumas foram encerradas e outras tiveram continuidade até os dias de hoje. As avaliações, em alguns casos, não atenderam as expectativas, como também nos acordos firmados entre os entes federativos partes não foram cumpridas. Dentre as principais resultados negativos das avaliações se deu pela a falta de acesso à internet, ou um acesso limitado.

Buscando sanar a dificuldade de acesso a internet nas escolas é que surgiram vários programas no atual PNE. O MEC, através do programa Educação Conectada, tinha como previsão a conexão de todas as escolas públicas brasileiras, até o final de 2018 e que o investimento maior seria estender e melhorar a infraestrutura e conexão das escolas.

\section{As tecnologias digitais em números: o que os dados apontam?}

Para verificar as repercussões das políticas públicas empreendidas nos últimos anos com vistas à expansão do uso das TDIC nas escolas brasileiras, passamos agora a analisar os dados educacionais. Foram utilizadas informações disponibilizadas pelos bancos do INEP, tanto os do Censo Escolar quanto os do SAEB a fim de se mapear aspectos da infraestrutura das escolas e do trabalho docente relativos à tecnologia. Os anos para a avaliação foram escolhidos tendo por base o início da vigência dos PNEs e nos quais tivessem sido realizadas edições da Prova Brasil do SAEB. Foram selecionados os anos de 2001 e 2015. 2017 também foi selecionado por ser o ano mais recente para quais, até a publicação deste texto, haviam dados disponibilizados.

O Censo Escolar é uma pesquisa declaratória realizada anualmente. O preenchimento da consulta é feito pelo responsável do estabelecimento escolar. Até 2006, a unidade de análise do Censo eram as escolas, e a partir de 2007, as 
questões passaram a ser distribuídas em quatro questionários: das escolas, das turmas, das matrículas e dos docentes. Alguns itens presentes no Censo podem ser usados para aferir a existência de recursos disponíveis para a utilização das TDIC. No questionário de 2001, constavam perguntas sobre presença de computadores e laboratórios de informática nas escolas, assim como acesso à internet e se a linha de internet era exclusiva para esse fim. O responsável pelo preenchimento ainda informava se os computadores da escola e a internet podiam ser utilizados para atividades pedagógicas. Por fim, o gestor era questionado sobre sua adesão ao Proinfo.

A partir de 2007, com a mudança de metodologia do Censo, algumas perguntas foram acrescentadas e outras foram atualizadas permitindo a obtenção de novas informações. No questionário das escolas, além da presença ou ausência de computadores no estabelecimento escolar, é questionado também sobre o número de computadores e quantos deles são disponibilizados para o uso dos alunos. Neste mesmo questionário, o responsável pelo preenchimento é instado a responder se existe acesso à internet e se sim, se é por meio de banda larga. Apesar de sua abrangência, uma vez que é realizado por todas as escolas do país, o Censo Escolar tem como limitação o fato de que os questionários somente permitem a verificação da presença ou ausência do item, sem, no entanto, possibilitar a avaliação da utilização, da qualidade ou do estado de conservação do recurso.

Essa limitação do Censo é, em parte, contornada pelo SAEB, no qual seus questionários contextuais permitem uma aproximação dos dados no tocante à sua utilização e qualidade. Composto por um conjunto de avaliações externas em larga escala, sendo a maior e mais abrangente a Avaliação Nacional do Rendimento Escolar (ANRESC, mais conhecida como Prova Brasil), o SAEB tem como objetivo realizar um diagnóstico da educação básica brasileira e de alguns fatores que possam interferir no desempenho do estudante, fornecendo um indicativo sobre a qualidade do ensino ofertado. O SAEB compreende questionários a serem preenchidos pelos alunos durante a realização do exame, pelos professores e pelos diretores, que preenchem também um formulário sobre os dados da escola. 
Quanto aos recursos relativos às TDIC, o questionário das escolas pergunta ao diretor se existem e quais as condições de uso de computadores para alunos, acesso à internet para uso dos alunos, acesso à internet para o uso dos professores, internet com conexão banda larga. Quanto aos espaços escolares, o questionário inquire sobre laboratório de informática. No questionário dos professores, é perguntado aos docentes se eles consideram a necessidade de aperfeiçoamento profissional quanto ao uso pedagógico das TDIC. Além disso, questiona também se utilizam programas/aplicativos pedagógicos para computadores e internet.

Apesar do avanço em relação às possibilidades analíticas dos dados, o SAEB apresenta como limitação a sua abrangência. Como a Prova Brasil só é aplicada em estabelecimentos escolares com mais de 20 matrículas do ensino fundamental, uma parte significativa das escolas brasileiras, especialmente as de menor porte - como as localizadas em áreas rurais, e que historicamente apresentam os maiores déficits em relação a recursos - não são avaliadas. Nesse sentido, para os objetivos deste artigo, foram utilizados os dados de ambos os bancos a fim de se avaliar as repercussões das políticas públicas de expansão do uso das TDIC nas escolas do país e empreender um esforço para verificação da sua qualidade.

A Tabela 1 compara a presença de itens de TDIC para os anos de 2001, 2015 e 2017. É possível perceber um movimento de melhoria significativa no interstício 2001-2015 seguido de uma piora entre 2015-2017. O salto qualitativo no primeiro ciclo pode ser atribuído ao esforço empreendido pelas políticas para mudar a situação de inércia inicial. Essa inércia pode ser inferida pela precariedade da infraestrutura das escolas quanto a itens básicos para a utilização de tecnologia quando se iniciou a vigência do PNE 2001-2010. Os dados do Censo Escolar confirmam o diagnóstico: menos da metade das escolas brasileiras possuíam computadores, os laboratórios de informática estavam limitados à cerca de $10 \%$ das escolas nacionais e a utilização da internet dependia do compartilhamento da rede telefônica. 
Todos os recursos de TDIC se reduziram no intervalo 2015-2017, sendo a queda mais expressiva a relativa aos laboratórios de informática (6 p.p.).

\section{Tabela 1}

Presença de itens relativos ao uso de tecnologia na educação básica no Brasil (20012017)

\begin{tabular}{l|cc|cc|cc}
\hline \multicolumn{1}{r}{ Localização } & \multicolumn{2}{c|}{2001} & \multicolumn{2}{c}{2015} & \multicolumn{2}{c}{2017} \\
& Rural & Urbana & Rural & Urbana & Rural & Urbana \\
\hline Número de escolas & 112.573 & 72.231 & 64.129 & 84.073 & 60.113 & 85.077 \\
Laboratório de & & & & & & 105 \\
Informática & $0,4 \%$ & $13 \%$ & $23,6 \%$ & $60,6 \%$ & $20,2 \%$ & $54,1 \%$ \\
Computadores & $2,9 \%$ & $45,6 \%$ & $50,5 \%$ & $94,8 \%$ & $51,6 \%$ & $92 \%$ \\
Internet & $0,2 \%$ & $15,4 \%$ & $23,8 \%$ & $85,3 \%$ & $31,6 \%$ & $83,9 \%$ \\
Conexão de qualidade* & $0,1 \%$ & $6,6 \%$ & $13,3 \%$ & $72,4 \%$ & $19 \%$ & $70,8 \%$ \\
\hline
\end{tabular}

Fonte: Elaborado a partir de dados de INEP/BRASIL, 2001; 2015; 2017.

* Para o ano de 2001, conexão de qualidade se refere a cabo telefônico exclusivo para o uso da internet. Para 2015 e 2017, conexão de qualidade se refere a presença de internet de banda larga.

Para o ano de 2001, o Censo questionava se os computadores presentes na escola eram utilizados para fins pedagógicos. Somente em 1.131 escolas (1\% do total) em áreas rurais e 14.620 (20,2\%) em áreas urbanas os computadores eram utilizados nas relações de ensino e aprendizagem. Ou seja, em comparação com a Tabela 1, essas informações revelam que uma parte considerável das escolas, mesmo possuindo computadores, não os destinava para práticas escolares, ou subutilizando-os ou os reservando apenas para setores administrativos. Também foi perguntado se os laboratórios de informática eram utilizados para práticas pedagógicas. Mesmo 9.419 escolas urbanas respondendo que o estabelecimento constava desse espaço escolar, destes, mais de 1.500 laboratórios não eram utilizados para aulas. Por fim, para o ano de 2001, as escolas eram instadas a responderem sobre a adesão ao Proinfo. De um universo de 184.804 escolas, apenas 4.142 aderiram ao programa (270 escolas de áreas rurais e 3.872 escolas de áreas urbanas). 
Nos anos de 2015 e 2017 os dados do Censo informam sobre o número de computadores na escola e quantos destes computadores são destinados aos alunos. As Tabela 2 e 3 apresentam a estatística descritiva desses dados.

\section{Tabela 2}

Estatística descritiva do número de computadores nas escolas brasileiras (2015-

\begin{tabular}{|c|c|c|c|c|}
\hline \multicolumn{5}{|c|}{ 2017） } \\
\hline \multirow{2}{*}{$\begin{array}{r}\text { Ano } \\
\text { Localização }\end{array}$} & \multicolumn{2}{|c|}{2015} & \multicolumn{2}{|c|}{2017} \\
\hline & Rural & Urbana & Rural & Urbana \\
\hline Média & 3,61 & 16,64 & 3,46 & 14,34 \\
\hline Mediana & 1 & 13 & 1 & 10 \\
\hline Desvio padrão & 11,67 & 34,69 & 11,84 & 28,08 \\
\hline Coeficiente de variação & $323 \%$ & $208 \%$ & $342 \%$ & $195 \%$ \\
\hline
\end{tabular}

Fonte: Elaborado a partir de dados de INEP/BRASIL, 2001; 2015; 2017.

\section{Tabela 3}

Estatística descritiva do número de computadores para alunos nas escolas brasileiras (2015-2017)

\begin{tabular}{|c|c|c|c|c|}
\hline \multirow{2}{*}{$\begin{array}{r}\text { Ano } \\
\text { Localização }\end{array}$} & \multicolumn{2}{|c|}{2015} & \multicolumn{2}{|c|}{2017} \\
\hline & Rural & Urbana & Rural & Urbana \\
\hline Média & 2,29 & 11,27 & 2,26 & 9,71 \\
\hline Mediana & $\mathrm{O}$ & 10 & $\mathrm{O}$ & 5 \\
\hline Desvio padrão & 7,24 & 18,94 & 7,34 & 18,84 \\
\hline Coeficiente de variação & $316 \%$ & $168 \%$ & $324 \%$ & $194 \%$ \\
\hline
\end{tabular}

Fonte: Elaborado a partir de dados de INEP/BRASIL, 2001; 2015; 2017.

A leitura das Tabelas 2 e 3 permite dimensionar a grande desigualdade em relação a adequação das escolas para a utilização de TDIC. Os altos coeficientes de variação indicam a existência de valores extremos que afetam a média. Dessa forma, para fins de análise, a mediana é mais adequada para averiguar o número de computadores presentes nas escolas brasileiras, e quantos destes são destinados aos estudantes da educação básica. Pelo menos metade dos estabelecimentos escolares em 2015 tinha até 13 computadores na escola e 10 para alunos. Esse número reduziu consideravelmente em 2017, caindo para a metade em relação aos computadores para os alunos. Em outras palavras, as Tabelas 2 e 3 desvelam que em 2017, ainda que 92\% das escolas urbanas do país 
tenham computadores (Tabela 1), pelo menos a metade delas os têm em número reduzido para o trabalho pedagógico. Em números absolutos, os dados do Censo Escolar de 2017 revelam a coexistência de escolas com 788 e 1.950 computadores para estudantes (valores máximos para áreas rurais e urbanas, respectivamente) ao mesmo tempo com escolas sem nenhum equipamento reservado para os estudantes.

O SAEB 2001 questionou aos professores se o acesso à internet e o uso de computadores são utilizados como recursos pedagógicos. A maioria dos docentes respondeu que não utiliza esses recursos de TDIC, pois a escola não está equipada, embora considerem importantes itens para a prática docente. Naquele ano, menos de $5 \%$ dos professores de escolas públicas rurais brasileiras que responderam ao questionário utilizavam computadores com seus alunos e menos de $2 \%$ usavam internet. Nas escolas públicas de áreas urbanas, cerca de um em cada quatro professores $(25,7 \%)$ utilizava computadores como recurso didático, apesar do acesso à internet para esse fim estivesse restrito a menos de $15 \%$ das escolas. 3,7\% dos professores das áreas urbanas informaram que não utilizavam a internet como recurso pedagógico por não considerarem esse uso importante. Ainda que esse percentual seja relativamente pequeno, em termos absolutos, expressa um número significativo de docentes (14.693 professores). A figura1 apresenta os gráficos de como essas respostas estão distribuídas nas áreas rurais e urbanas. 
Acesso à internet

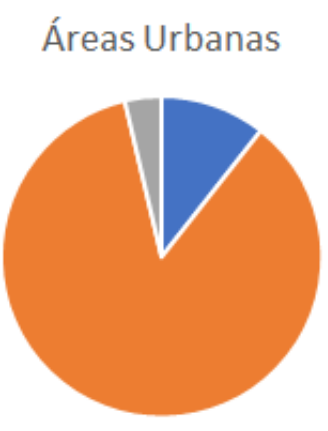

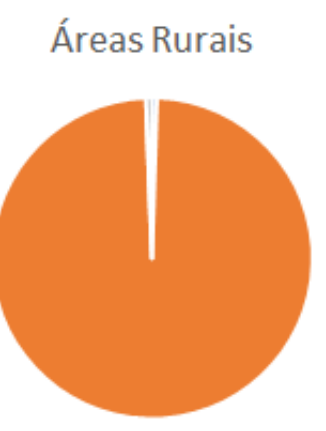
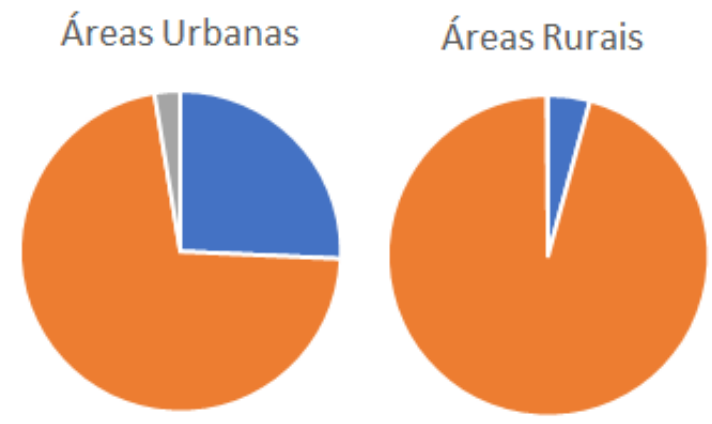

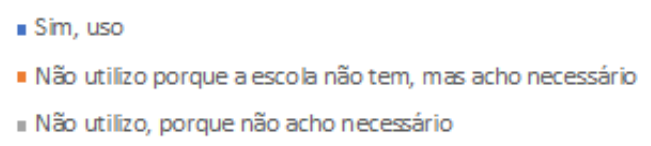

Figura 1 Utilização de recursos de TDIC para fins pedagógicos, segundo respostas de professores, em escolas públicas de áreas urbanas e rurais, 2001.

Fonte: Elaborado a partir de dados de INEP/BRASIL, 2001b.

Os dados do SAEB de 2015 e 2017 apresentam novas informações, dentre elas, a presença e condições de uso de computadores e acesso à internet para alunos e professores, se a internet é de banda larga, se existe laboratório de informática (questionário das escolas). Os professores também informaram nesses anos sentiam a necessidade de aperfeiçoamento profissional quanto ao uso das TDIC e se utilizavam programas/aplicativos de computador e internet com fins pedagógicos (questionário dos professores).

As informações relativas às condições de uso dos computadores corroboram com os dados do Censo Escolar (tabelas 1 e 2). Para as escolas urbanas, entre os anos de 2015 e 2017 o percentual de computadores em bom estado de uso caiu pela metade (de 42,6\% para 27,2\%). Por outro lado, aumentaram os percentuais de escolas com condições de uso dos computadores ruins e mais que dobraram os de escolas sem computadores (de $12,9 \%$ para $15 \%$, e de $14,8 \%$ para $32,7 \%$, respectivamente). Nas escolas rurais todos os percentuais diminuíram uma vez que mais da metade das escolas responderam que o item era inexistente (saindo de $34,6 \%$ em 2015 para $58,2 \%$ em 2017). Esse movimento pode ser percebido nos gráficos da Figura 2. 


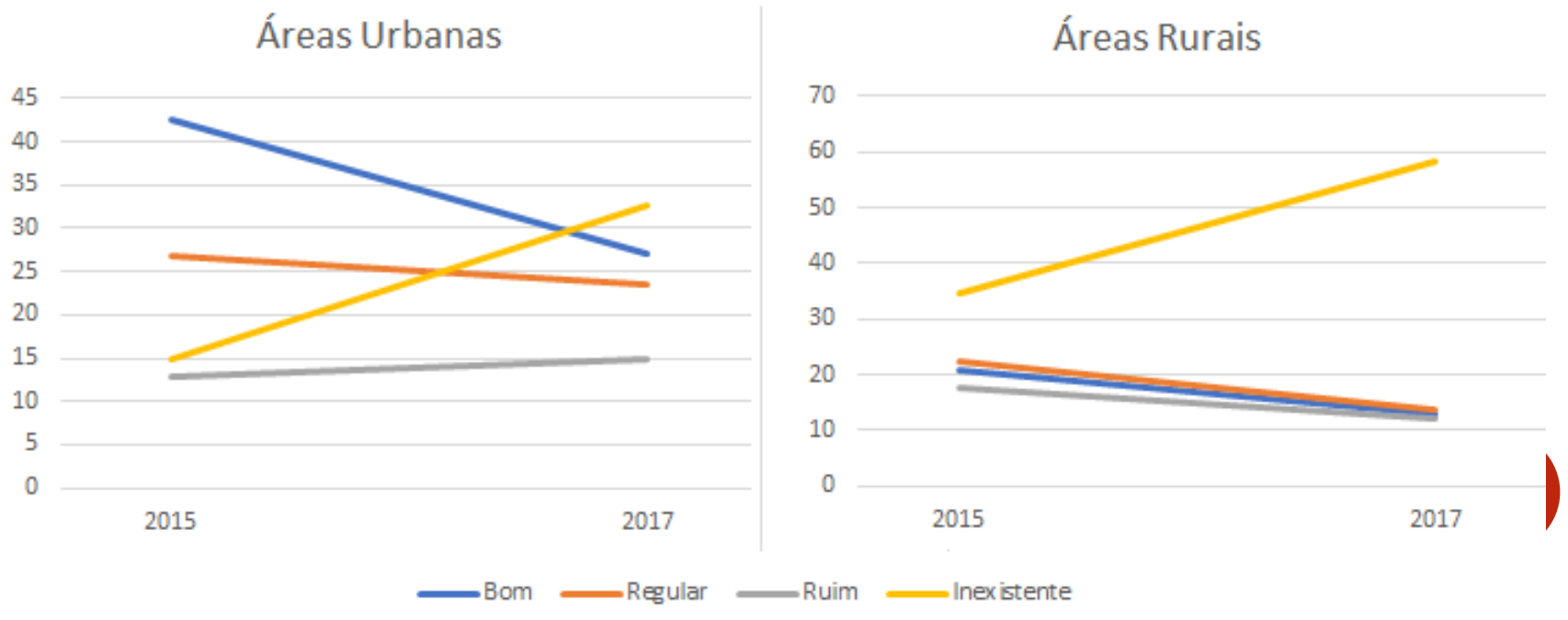

Figura 2 Condições de uso de computadores para atividades pedagógicas com alunos em escolas públicas de áreas urbanas e rurais (2015-2017).

Fonte: Elaborado a partir de dados deINEP/BRASIL, 2015b, 2017b.

Padrão semelhante é encontrado quando se analisa a internet, internet banda larga e laboratório de informática. Indo no mesmo sentido dos dados do Censo, é possível constatar uma piora significativa tanto na presença desses itens em escolas públicas urbanas e rurais no país quanto as suas condições e estado de conservação (Figura 2). Uma possível explicação para a diminuição e a queda da qualidade de todos os itens é a não renovação e atualização de programas de adequação da infraestrutura das escolas quanto ao uso das TDIC. A medida que a tecnologia avançou, alguns equipamentos podem ter se tornado obsoletos o que levou a sua deterioração e paulatino abandono por parte dos profissionais da escola. A falta de manutenção e troca de peças e componentes defeituosos pode também servir de fator explicativo para a inexistência e/ou piora dos itens. No entanto, essa explicação, plausível para os equipamentos, não nos parece adequada para a diminuição da avaliação positiva ('Bom') para a internet dos alunos não seguida da diminuição na mesma proporção das condições da internet banda larga. 

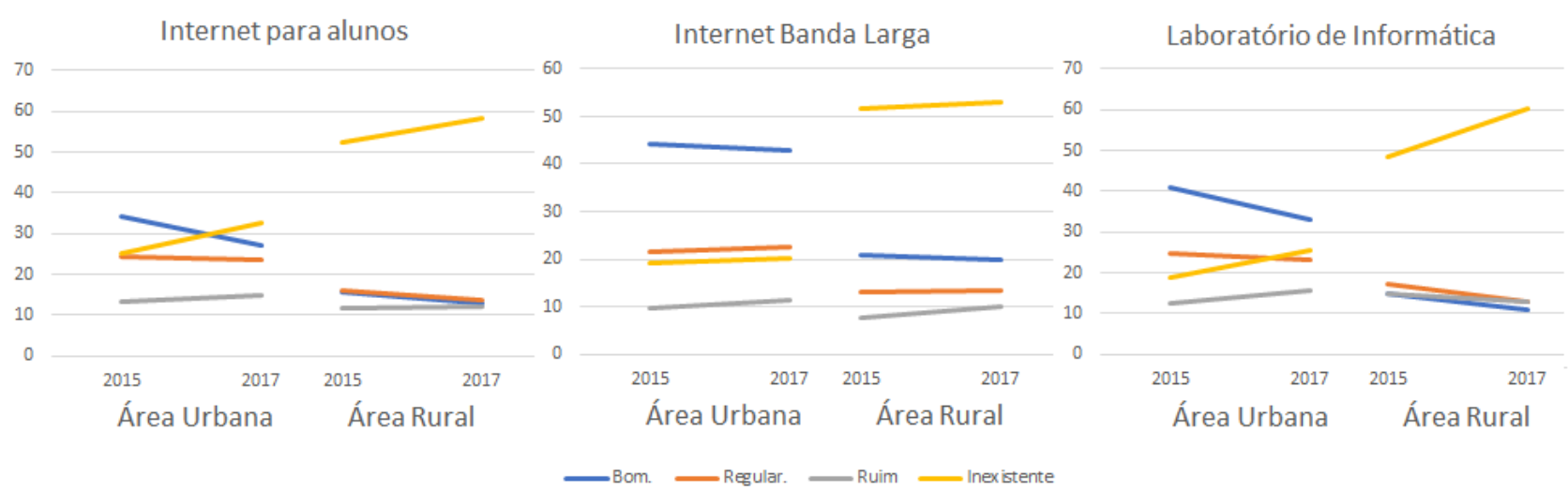

Figura 3Condições de uso de internet, internet banda larga e laboratórios de informática para atividades pedagógicas com alunos em escolas públicas de áreas urbanas e rurais (2015-2017).

Fonte: Elaborado a partir de dados de INEP/BRASIL, 2015b, $2017 \mathrm{~b}$.

Respondendo sobre a necessidade de curso de aperfeiçoamento para o uso pedagógico das TDIC, os números praticamente se mantiveram no período entre 2015 e 2017 (Figura 4). O maior percentual de respostas considerou a necessidade moderada de programas de capacitação e formação docente.

\section{Área Urbana Área Rural}

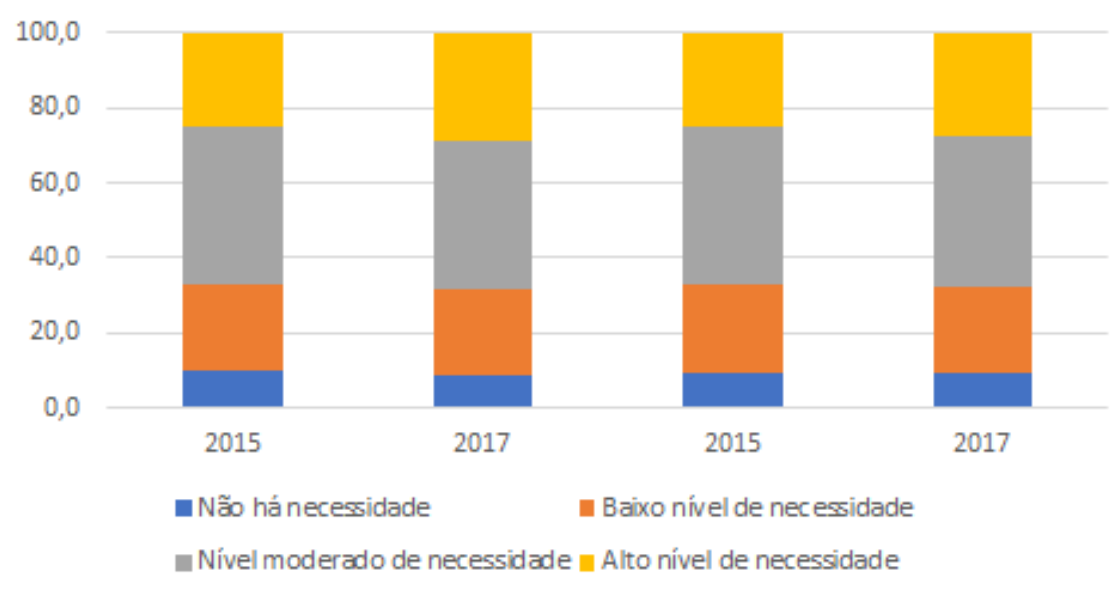

Figura 4 Percepção de professores sobre a necessidade de cursos de aperfeiçoamento para uso de TDIC em escolas públicas de áreas urbanas e rurais (2015-2017). Fonte: Elaborado a partir de dados de INEP/BRASIL, 2015b, 2017b.

As duas últimas tabelas são distribuições de frequência das respostas dos professores das escolas públicas nos questionários contextuais do SAEB quanto ao uso de programas e aplicativos de computador, bem como de internet em suas aulas (Tabelas 4 e 5). As variações são pequenas entre os anos e levado em 
conta a localização. Há uma ligeira diminuição no percentual de professores que utilizam sempre programas e aplicativos ao mesmo tempo em que sobe o número de escolas que não os têm. Nas áreas rurais, apesar do aumento do número de escolas sem os recursos, em contrapartida, se ampliou o percentual de docentes que os utilizam sempre (Tabela 4).

\section{Tabela 4}

Percentual de professores de escolas públicas de áreas urbanas e rurais que utilizam programas e aplicativos de computador em aula (2015-2017)

\begin{tabular}{|c|c|c|c|}
\hline Localização & Resposta & 2015 & 2017 \\
\hline \multirow{5}{*}{ Urbana } & Não utilizo porque a escola não tem & 12,4 & 13,2 \\
\hline & Nunca & 19,3 & 19,6 \\
\hline & De vez em quando & 48,4 & 48,6 \\
\hline & Sempre ou quase sempre & 20,0 & 18,6 \\
\hline & Total & 100 & 100 \\
\hline \multirow{5}{*}{ Rural } & Não utilizo porque a escola não tem & 22,5 & 23,1 \\
\hline & Nunca & 20,4 & 18,6 \\
\hline & De vez em quando & 41,6 & 41,6 \\
\hline & Sempre ou quase sempre & 15,5 & 16,7 \\
\hline & Total & 100 & 100 \\
\hline
\end{tabular}

Fonte: Elaborado a partir de dados de INEP/BRASIL, 2015b, 2017b.

Houve uma melhora nos percentuais dos professores que responderam utilizar a internet em suas aulas entre 2015 e 2017. Esse aumento foi mais expressivo nas áreas rurais conforme pode ser visto na Tabela 5 (cerca de 6 p.p.). No entanto, dado que na mesma avaliação, os responsáveis pelo preenchimento do formulário das escolas apontaram a diminuição de internet (já apontado na análise da Figura 2), é de se supor que os professores possam estar utilizando outra forma de acesso à internet, que não a da escola - como, por exemplo, a pessoal. 


\section{Tabela 5}

Percentual de professores de escolas públicas de áreas urbanas e rurais que utilizam internet em aula (2015-2017)

\begin{tabular}{l|l|c|c}
\hline Localização & Resposta & $\mathbf{2 0 1 5}$ & $\mathbf{2 0 1 7}$ \\
\hline \multirow{2}{*}{ Urbana } & Não utilizo porque a escola não tem & 10,3 & 9,6 \\
& Nunca & 11,8 & 9,9 \\
& De vez em quando & 45,0 & 43,9 \\
& Sempre ou quase sempre & 32,8 & 36,6 \\
& Total & 100 & 100 \\
Não utilizo porque a escola não tem & 21,5 & 18,7 \\
& Nunca & 13,7 & 9,8 \\
Rural & De vez em quando & 36,5 & 36,8 \\
& Sempre ou quase sempre & 28,3 & 34,7 \\
& Total & 100 & 100 \\
\hline
\end{tabular}

Fonte: Elaborado a partir de dados de INEP/BRASIL, 2015b, $2017 \mathrm{~b}$.

\section{Considerações finais}

O intenso desenvolvimento e expansão das TDIC nas últimas décadas do século XX e início do XXI fizeram com que os poderes públicos passassem a empreender políticas de expansão e democratização do acesso às tecnologias digitais em suas redes de ensino da educação básica. A situação de grande precariedade inicial das escolas nesse aspecto exigiu grande dispêndio de recursos no empreendimento de políticas de alcance nacional nos anos 2000 que se refletiram em uma saída da situação de inércia e uma significativa expansão do atendimento naquela década. Se no início dos anos 2000 menos da metade das escolas urbanas tinham computadores, em 2017 mais 90\% das escolas já estavam equipada com esse recurso. Da mesma forma a internet, antes limitada a menos de 10\% das escolas, hoje está disponível na modalidade de banda larga para 3 em cada 4 estabelecimentos escolares localizados nas cidades.

No entanto, os dados apontam que a desigualdade entre áreas urbanas e rurais ainda persiste: para as escolas rurais, pouco menos da metade permanece sem computadores e mais de $80 \%$ não tem acesso à internet de qualidade. Apesar 
das políticas, em média, o número de computadores por escola para a utilização dos alunos é insuficiente para a prática didática. Além disso, os dicionários contextuais do SAEB apontam que a qualidade do equipamento tem se deteriorado com os anos, nos permitindo inferir que o movimento inicial de expansão das TDIC nos anos 2000 não foi acompanhado por uma política de atualização e manutenção dos aparelhos, tornando parte significativa deles obsoletos e inoperantes. Mesmo com a redução de preços de acesso à internet de qualidade, o acesso a esse item se reduziu ou piorou nas escolas urbanas e rurais. Isso se reflete na resposta dos docentes, onde aproximadamente um em cada três professores brasileiros não utiliza computadores ou internet com seus alunos.

$\mathrm{O}$ uso das TDIC nas relações de ensino-aprendizagem no Brasil ainda encontra grandes desafios e longo caminho para a efetivação. As políticas públicas, ainda que tenham alcançado certo êxito, sobretudo nos anos 2000, onde a precariedade era a regra, encontraram limites para a utilização contínua, manutenção e atualização. Faz-se necessário que os poderes públicos coordenem suas ações de forma a cumprir os objetivos traçados na legislação, sobretudo, para o alcance das metas do PNE 2014-2024. Assim, o Brasil poderá entrar de fato no século XXI e proporcionar aos alunos e alunas da educação básica acesso às tecnologias digitais nas escolas para fins didáticos, se integrando plenamente a um mundo cada vez mais informatizado. 


\section{Referências}

ALMEIDA, M. E. B.; VALENTE, J. A. Tecnologias e currículo: trajetórias convergentes ou divergentes? São Paulo: Paulus, 2011.

BELLONI, M. L.Educação à distância. 4. ed. Campinas: Autores Associados, 2006.

BELLONI, M. L.; GOMES, N. G. Infância, mídias e aprendizagens: cenários de mudança. Educação e Sociedade. Campinas, v. 29, n. 104, p. 717-746, 2008.

BRASIL. Lei n. 13.005, de 25 de junho de 2014. Aprova o Plano Nacional de Educação - PNE e dá outras providências. Diário Oficial da União, Brasília, DF, 26 jun. 2014. Disponível em:http://pne.mec.gov.br/18-planos-subnacionais-deeducacao/543-plano-nacional-de-educacao-lei-n-13-005-2014. Acesso em: 5 abr. 2015.

BERTOLDO,H;SALTO,F., MILL, D. TDIC (tecnologia digitais da informação e comunicação). In: MILL, D. Dicionário Crítico de Educação e Tecnologias e de Educação a Distância. Campinas: Papirus, 2018.

FONTANA, Fabiana Fagundes; CORDENONSI, André Zanki. TDIC como mediadorado processo de ensino-aprendizagem da arquivologia. ÁGORA, Florianópolis, v. 25,n. 51, p. 101-131, jul./dez. 2015.

FREIRE, P. Pedagogia da autonomia: saberes necessários à prática educativa. 25. ed. São Paulo: Paz e Terra, 2002.

FREIRE, Paulo; GUIMARÃES, Sérgio. Educar com a mídia. São Paulo:Paz e Terra, 2011.

KENSKI, Vani Moreira. Educação e tecnologias: o novo ritmo da informação. 8. ed.Campinas, SP: Papirus, 2012.

MORAES, M.C. Paradigma educacional emergente. São Paulo: Papirus, 1997.

PAPERT, S. A máquina das crianças: repensando a escola na era da informática. Porto Alegre: Artes Médicas, 1994.

VALENTE, J. A. (Org.). O computador na sociedade do conhecimento. Campinas: UNICAMP/NIED, 1999. 